\title{
Prevention of headache after lumbar puncture: questionnaire survey of neurologists and neurosurgeons in United Kingdom:
}

\author{
M G Serpell, G J Haldane, D R S Jamieson, D Carson
}

The aetiology of headache after lumbar puncture is related to the hole left in the dura after the needle has been withdrawn, which allows the cerebrospinal fluid to leak out of the subarachnoid space. The headache can persist for prolonged periods and predispose to subdural haematomas, which are associated with a high mortality. Tourtellotte showed that this headache could be significantly reduced by using smaller needles. ${ }^{1}$ Also, among needles of the same size, those with atraumatic blunt tips are associated with a lower incidence of headache. They produce a smaller hole in the dura by separating rather than cutting the elastic fibres, as occurs with the Quincke tipped needles. ${ }^{2}$

We carried out a questionnaire survey of departments of neurology and neurosurgery to see if these needles were used in the practice of diagnostic lumbar puncture and to assess how else departments may be trying to prevent headaches after lumbar puncture.

\section{Methods and results}

In September 1996 we sent a questionnaire addressed to the "senior registrar" of all $(n=105)$ departments of neurology and neurosurgery in the United Kingdom, as listed by the Association of British Neurologists and the Society of British Neurological Surgeons. We asked specific questions about the practice in their department of diagnostic lumbar puncture. We sent a repeat questionnaire to non-respondents two months later.

The table shows the results of the survey. Seventy one departments (68\%) replied. Most departments performed lumbar puncture with the patients lying on their side. Equal proportions of neurology and neurosurgery departments used the 20 gauge spinal needles (the most commonly used needle in both groups). The Quincke tipped spinal needle was used by over $70 \%$ of departments in each specialty, and only about a third of departments in each specialty oriented the bevel of the needle tip to be parallel to the longitudinal axis of the spinal cord. Over $80 \%$ of the departments clinicians used bed rest as a prophylactic measure. Neurology departments were more likely than neurosurgery departments to use systemic steroids and epidural blood patch for the treatment of headache after lumbar puncture.

\section{Comment}

Although the response relies on one person's impressions of the practice of a whole department, we chose a senior trainee who would probably be exposed to most other members.

Most departments performed lumbar punctures with patients lying on their side, but it is quicker and technically easier with the patient sitting upright. Only about a third of departments used the correct orientation of the bevel of a Quincke tipped needle to the
Results of questionnaires from 71 departments of neurology and neurosurgery. Values are numbers (percentages) of departments unless stated otherwise

\begin{tabular}{lccc} 
Item & $\begin{array}{c}\text { Neurological } \\
\text { units }(\mathbf{n}=\mathbf{4 8})\end{array}$ & $\begin{array}{c}\text { Neurosurgical } \\
\text { units }(\mathbf{n}=\mathbf{2 3})\end{array}$ & P value \\
\hline Response rate & $48 / 64(75)$ & $23 / 41(56)$ & $0.04^{*}$ \\
\hline Patient position: & $1(2)$ & 0 & \\
\cline { 1 - 3 } Sitting & $44(92)$ & $22(96)$ & \multirow{2}{*}{ NS } \\
\cline { 1 - 3 } Lying on side & $3(6)$ & $1(4)$ & \\
\cline { 1 - 3 } Either position & & & \\
\hline
\end{tabular}

Smallest needle size used:

\begin{tabular}{|c|c|c|c|}
\hline 18 gauge & $6(12)$ & $4(17)$ & \\
\hline 20 gauge & $23(48)$ & $12(52)$ & \\
\hline 22 gauge & $13(27)$ & $6(26)$ & NS \\
\hline 24 gauge & $2(4)$ & 0 & \\
\hline
\end{tabular}

Doed

Needle type:

\begin{tabular}{lcc}
\hline Quincke tip & $34(71)$ & $17(74)$ \\
\cline { 1 - 2 } Atraumatic tip & $7(15)$ & $3(13)$ \\
\cline { 1 - 3 } Respondent did not answer & $7(15)$ & $3(13)$
\end{tabular}

question or used both types

Position of needle tip relative to longitudinal axis of spinal cord:

\begin{tabular}{|c|c|c|c|c|}
\hline \multicolumn{4}{|c|}{ osition of needle tip relative to longitudinal axis of spinal cord: } & \multirow{4}{*}{$\begin{array}{l}\text { Correspondence to: } \\
\text { Dr Serpell } \\
\text { mgserpell@altavista. } \\
\text { net }\end{array}$} \\
\hline Parallel & $15(31)$ & $9(39)$ & \multirow{3}{*}{0.7} & \\
\hline Perpendicular & $17(35)$ & $6(26)$ & & \\
\hline Not considered & $16(33)$ & $8(35)$ & & \\
\hline
\end{tabular}

$\begin{array}{cccc}\begin{array}{c}\text { Mean (range) volume (ml) of } \\ \text { cerebrospinal fluid collected }\end{array} & 8 \text { (2 to 30) } & 8 \text { (1 to 20) } & 0.9\end{array}$ BMJ 1998;316:1709-10

Mean acceptable incidence

(\%) of headache after

lumbar puncture (range)

Prophylactic bed rest after lumbar puncture:

\begin{tabular}{|c|c|c|c|}
\hline Not practised & $8(17)$ & $5(22)$ & \multirow{3}{*}{0.8} \\
\hline For $1-6$ hours & $35(73)$ & $15(65)$ & \\
\hline For 6-24 hours & $5(10)$ & $3(13)$ & \\
\hline \multicolumn{3}{|c|}{ Treatment of headache after lumbar puncture } & \\
\hline $\begin{array}{l}\text { Respondent suggested } \\
\text { systemic steroids }\end{array}$ & $22(46)$ & $2(9)$ & \multirow{2}{*}{$0.002^{*}$} \\
\hline $\begin{array}{l}\text { Respondent did not suggest } \\
\text { systemic steroids }\end{array}$ & $26(54)$ & $21(91)$ & \\
\hline \multicolumn{3}{|l|}{ Epidural blood patch: } & \\
\hline Considered before 72 hours & $4(8)$ & $3(13)$ & \multirow{4}{*}{0.055} \\
\hline Considered after 72 hours & $27(56)$ & $5(22)$ & \\
\hline No response & $11(23)$ & $9(39)$ & \\
\hline Don't know & $6(12)$ & $6(26)$ & \\
\hline
\end{tabular}

NS=not significant as determined by Fisher's exact probability test. *With $\chi^{2}$ test.

dura. Mihic proved that the incidence of headache when a Quincke tipped needle was used was reduced if the bevel of the cutting edge was parallel to the longitudinal dural fibres. ${ }^{3}$

The frequency of headache after diagnostic lumbar puncture with 20 and 22 gauge Quincke needles in ambulatory patients is $36 \% .{ }^{4} \mathrm{In}$ our survey both groups thought that an acceptable rate would be less than half this rate, even though they used a similar needle. Atraumatic needles of this gauge can be used just as effectively to obtain fluid samples and manometry readings and would also reduce the incidence of head-
Department of

Anaesthesia,

Western Infirmary,

Glasgow G11 6NT

M G Serpell,

consultant

anaesthetist

G J Haldane,

specialist registrar

Institute of

Sciences, Southern

General Hospital

NHS Trust,

Glasgow G51 4TF

D R S Jamieson,

clinical lecturer

Department of

Anaesthesia, Ulster

Hospital,

Dundonald, Belfast

BT16 0RH

D Carson,

consultant

anaesthetist

Correspondence to: Dr Serpell

BMJ 1998;316:1709-10
Neurological 
ache. ${ }^{2}$ Bed rest was commonly practised despite having no value in the prevention of headache. ${ }^{5}$

Treatment of established headache after lumbar puncture includes hydration, analgesics, vasopressin, and caffeine. More invasive techniques include the installation of saline or autologous blood into the epidural space. The latter procedure (epidural blood patching) has a success rate of $90 \%$ with only minor short term sequelae. Very few of the departments in our study said that they would consider this option within the first 72 hours, although early use is strongly advocated in anaesthetic circles. This may be because other causes of the headache are more likely or because the patient has a fever, which precludes blood patching. However, epidural blood patching would be considered by a good proportion of neurologists after 72 hours.

We thank all those who took the time and effort to respond to our questionnaire.
Contributors: MGS and DC initiated the research. MGS participated in the study design, data collection, analysis, interpretation, and writing of the paper and will act as guarantor. GJH participated in data collection, analysis, interpretation, and writing of the paper. DRSJ participated in the study design and the interpretation and, together with DC, edited the paper.

Funding: None.

Conflict of interest: None.

1 Tourtellotte WW, Henderson WG, Tucker RP, Gilland O, Walker JE, Kokman E. A randomised, double blind clinical trial comparing the 22 versu 26 gauge needle in the production of the post-lumbar puncture syndrome in normal individuals. Headache 1972;12:73-8.

2 Carson D, Serpell M. Choosing the best needle for diagnostic lumbar puncture. Neurology 1996;47:33-7.

3 Mihic DN. Postspinal headache, needle surface and longitudinal orientation of the dural fibres. Results of a survey. Reg Anesth 1986;9:54-6.

4 Kuntz KM, Kohmen E, Stevens JC, Miller P, Offord KP, Ho MM. Post-lumbar puncture headaches: experience in 501 consecutive procedures. Neurology 1992;42:1884-7.

5 Carbaat PAT, VanCrevel H. Lumbar puncture headache. Controlled study in the preventive effect of 24 hours bed rest. Lancet 1981;ii:1133-5. (Accepted 3 December 1997)

\title{
Problems in retrieving national data on births: questionnaire survey
}

\author{
Lesley Smith
}

King's Fund, London W1M 0AN Lesley Smith, researcher for CESDI colls@kehf.org.uk

BMJ 1998;316:1710-1
Although more data on maternal and child health are being collected locally, the amount of data available nationally has fallen over the past decade. ${ }^{1}$ Central sources of data exist in England and Wales, but clinical data are limited (Office for National Statistics registrations) or of poor quality (maternity hospital episode system, patient episode data Wales). ${ }^{2}$ Only Northern Ireland (child health record system) and Scotland (Scottish Morbidity Record-SMR2) provide good quality data on maternal and child health. ${ }^{3}$

If national data were available, trends in health care as well as morbidity and mortality for rare conditions could be analysed. National data would also be useful to the confidential inquiry into stillbirths and deaths in infancy (CESDI)-the survey that covers fetal and infant deaths between 20 weeks' gestation and 1 year in England, Wales, and Northern Ireland. The numerator data collected through the survey's rapid reporting process cannot be interpreted without national

Difficulties met by regional coordinators in generating regional data for 1993 and 1995 . Values are numbers of difficulties mentioned by coordinators

\begin{tabular}{lcc} 
Difficulties & $\begin{array}{c}\mathbf{1 9 9 3} \text { data } \\
(\mathbf{n = 1 5 )}\end{array}$ & $\begin{array}{c}\mathbf{1 9 9 5} \text { data } \\
\mathbf{( n = 1 3 )}\end{array}$ \\
\hline No central point covering region & 7 & $9^{*}$ \\
\hline Data were hospital based & 4 & $4 \dagger$ \\
\hline Quality of data in doubt & 4 & $3^{\star}$ \\
\hline Data aggregated or defined differently from confidential inquiry data & 3 & 3 \\
\hline Low priority given to providing regional data & 0 & 3 \\
\hline Lack of staff & 2 & 3 \\
\hline Data not totalled & 2 & $2^{\star}$ \\
\hline Incompatible, non-uniform information systems & 1 & $2^{*}$ \\
\hline Technical problems & 1 & 1 \\
\hline Fee requested & 1 & $?$ \\
\hline Data no longer available or available too late & 1 & 1 \\
\hline Data not available for research & 0 & 1 \\
\hline
\end{tabular}

*In one case, other sources indicate that difficulty still exists, but was not specifically mentioned by the coordinator in the 1996 survey.

†In all cases the difficulty still exists but was not specifically mentioned. denominator data. In recognition of this need, a study was carried out to determine whether population based data for 1993 and 1995 could be obtained from regional sources.

\section{Methods and results}

In 1993, as part of a study managed by the National Perinatal Epidemiology Unit, all district and regional public health departments were asked for information on sources of maternity and child health data. Systems for collecting either maternity or child health data were in place in almost every district. Six regions in England, Wales, and Northern Ireland operated uniform systems across former regional health authorities; five had a procedure or independent survey; and three had so many different systems that it would have been impossible to retrieve regional data.

In September 1994, all 16 regional coordinators for the confidential inquiry into stillbirths and deaths in infancy were sent a list of 22 data items and asked to identify those available from NHS sources for all babies delivered in 1993 to residents in their region. Fifteen lists were returned, and four common variables of gestation, time of delivery, parity, and onset of labour were chosen.

In January 1995, a form requesting population based aggregated 1993 data for the chosen variables (with clear definitions) was sent to nine regional coordinators. All were confident of producing results since similar data had been generated for their own reports. Four of the nine regions produced all the data requested. One region supplied half the data, which were hospital based and therefore unusable, and three regions could not generate any data.

In June 1996, 16 regional coordinators were sent a follow up questionnaire on 1995 data. Three did not respond-two did not wish to and one had not partici- 